\title{
A Bid to Acquire Qualifications and Credentials and Quality University Education in Kenya - a Lecturer's Dilemma
}

\author{
Diana Kerubo Agoki ${ }^{1}$, Belinda KisiaMaasai ${ }^{2}$ \\ ${ }^{1}$ Maasai Mara University; School of Business \& Economics; Department of Business Management; P. O. Box \\ 861- 20500, Narok - Kenya; \\ ${ }^{2}$ Mara University; School of Business \& Economics; Department of Business Management; P. O. Box 861- \\ 20500, Narok - Kenya;
}

\begin{abstract}
This paperqualitative desk - top research which aimed at highlighting the dilemma that the lecturers in Kenyan Universities find themselves in as they juggle their lives between publishing or perishing, providing Quality Education $(Q E)$ as per the provisions of Commission for University Education (CUE), and other stakeholders. The study was driven by CUE which has pointed out again and again that quality of university education has gone down; CUE criteria on lecturer upward mobility, United Nations Educational, Scientific and Cultural Organization (UNESCO) educational requirements and current National goals; and challenges facing lecturers in a bid to remain relevant. The study findings indicated that both qualifications and credentials are essential in providing QE; but without support in terms of funding, time, infrastructure is a mind-boggling task for lecturers; development of virtual universities and distant learning and for Kenya, devolution, matters of $Q E$ will become even more complex. Universities should find a mechanism of engaging all their stakeholders to establish structures for implementing the QE; incentives and rewards for university lecturers should be provided systematically and substantially with the linking of performance appraisal with research.The studyrecommendsthat the Government and CUE should rethink the double intakeand parallel programs;carefully invest in physical facilities, teaching and research resources and innovative Information Communication Technology (ICT). Individual Universities should invest in orientation and development programs for lecturers and develop niche programs and businesses to provide financing to improve their infrastructure. Finally, universities in Kenya should work with the industry and individual investors to: develop the ICT and other infrastructure to meet world stands; and this would help universities to be in touch with the industry requirements in terms of products' skills and core competencies.
\end{abstract}

Keywords: quality education; lecturer qualification and credentials; Lecturers' dilemma

\section{Background}

In Kenya, quality in universities was embraced some years back by facilitating the vigorous vetting of programs; matching the programs with the existing capacity and competent sourcing of human resources to run the programs. Credentials and qualifications are the two main guidelines that universities use in selecting and recruiting lecturers as directed by Commission for University Education. Credentials constitute abilities and experiences which make someone suitable for a particular job. Qualification refers to official evidence that one has completed some course and has the necessary knowledge and skill for the job. Lecturers' service determines the degree of effectiveness and the quality of the education administered. Therefore, in determining suitability for appointment or promotion, lecturers are evaluated on a basis of qualification, work experience, research and publication, quality teaching and learning, administration and responsibility, and community engagement and other contributions (CUE, 2014).

$\mathrm{QE}$ is defined from different dimensions due to the fact that different stakeholders are involved. The government, employers, educators, parents and the community all have their expectations which may not necessarily be in harmony. Besides, the recipient of the education also has expectations during the process of the education and; from the outcomes of the process. Survival and upward mobility of lecturers are based on credentials, especially conference attendance and publications. This creates a challenge for the lecturer who should balance accumulation of credentials and assembly of quality teaching materials and sometimes the quest for credentials prevails. It is worth noting that most of the public universities are very young and at formative stages and; competing globally. Development and restructuring of systems are all taking place simultaneously, bearing heavily on resources. Staff development therefore remains largely the responsibility of the lecturer in order for him/her to accumulate the credentials. Unlike in the corporate world where a new employee would be oriented and equipped with the resources of operating, it is the onus of the lecturer to creatively find resources both for teaching and self - development for teaching. This has its own implications for the lecturer and the other stakeholders. The aim of this paper is to discuss the dilemma that lecturers find themselves in as they 
juggle between 'publishing or perishing', providing QE as per the provisions of CUE(CUE, 2014), and remaining relevant in their fields of specialization in a very dynamic academic world in the back drop of no semester recess as semesters run back to back due to the double intake, privately sponsored students programs phenomena (CUE, 2014), and little or no funding for lecturer development and poor universities' infrastructure to support QE.

\subsection{Statement of the Problem}

Achievement of educational goals is reflective of $\mathrm{QE}$. That there have been many reviews of the educational system and that the list of goals only lengthens suggests that the systems have so far not produced the desired quality.The mediums for quality delivery arelecturers. Institutions of higher learning are the exit points of products of education into the job market. The performance of the products hence is tied to QE as imparted by the lecturers. There has been debate regarding the credentials of the lecturers in relation to the $\mathrm{QE}$ and whether lecturers should bear the brunt of the inadequacies of the higher educational system. The dilemma that the lecturers find themselves in as they juggle between publishing or perishing, providing QE as per the provisions of CUE and other stakeholders, achieving all these without any break as semesters run back to back due to the double intake, privately sponsored students programs phenomena(CUE, 2014), and little or no funding for lecturer development must be addressed.

\section{Review Of Relevant Literature}

\subsection{Quality}

Quality refers to an acquired trait; accomplishment; acquisition a superior birth or station; high rank; elevated character or that which makes, or helps to make, anything such as it is; anything belonging to a subject, or predicable of it; distinguishing property, characteristic, or attribute; peculiar power, capacity, or virtue; distinctive trait; as, the tones of a flute differ from those of a violin in quality; the great quality of a statesman(Newton, 2000). Quality is often used to signify the excellence of a product or a service. Quality refers to the state of meeting the customer's requirements which may be expressed as: 1) Fitness of purpose or use; 2) The totality of features and characteristics of a product or service that bear on its ability to satisfy stated or implied needs; and 3) Quality should be aimed at the needs of a customer - present and future(Demming, 1993). Whatever type of organization, the competition is real - for quality, reliability, prices and delivery, of which quality is now recognized as the very important of all these weapons.

Stakeholders demand include students, the parent, the lecturer, the institution, the sector/ministry of education, the market, the community, international organizations (like UNESCO), donors, regulating agencies, etc. Thinking about customers and their satisfaction is customer loyalty, in an organization's success. Research shows that a focus on customer loyalty can provide several commercial advantages: 1) Customers cost less to retain than to acquire; 2) The longer the relationship with the customer, the higher the profitability (customer equity); 3) A loyal customer will commit more spend to its chosen supplier; and 4) About fifty percent of customers come through referrals from existing clients (indirectly reducing acquisition costs). These advantages are desirable for universities if they are to achieve their missions and the national educational goals(Agoki, 2015).

\subsection{Total Quality Management (TQM) and QE}

Universities the world over are now scrambling forInternational Organization for Standardization (ISO) certification: which is a statement to stakeholders, employees and senior management that the business wishes to operate to a set framework in order to achieve its company objectives such as access to QE.TQMis an approach of improving competiveness and flexibility of a whole organization. TQM is a comprehensive and structured approach to organizational management that seeks to improve the quality of products and services through ongoing refinements in response to continuous feedback (Billing, 2004). It is a way of reducing waste through continuous improvement and it is dependent upon each individual at each level. The foundations of TQM hold that: 1) the organization needs a long-term commitment to constant improvement; 2) adopt the philosophy of zero errors /defects to change the culture to right-first-time; 3 ) train the people to understand customer-supplier relationship because customer orientation must be achieved for every employee and, the concept of the internal customer and supplier must be thoroughly understood; 4) products and services must not be bought on the basis of price alone, but the total cost to bring about improvement in products/services and failure rates; and 5) Recognize that the improvement of the system needs to be managed. The systems should be in line with needs and expectations and part of the continuous improvement process. 6) Adopt modern methods of supervision and training to eliminate fear (Demming, 1993). Mistakes/short-comings must be criticized and corrected and effort and achievements must be praised. 


\subsection{Educational/ Academic quality}

In view of TQM and quality, EQ is then a description of how well the learning opportunities available to students help them achieve their award. It is ensuring that appropriate and effective teaching, research, support, assessment and learning opportunities are provided (Billing, 2004). In marketing terms education is a service whose outcome is to equip the learner with skills to meet the needs of the job market. The complexity of the graduate as a product is in the packaging of the same (graduate) such that he/she meets the expectations of all the stakeholders (quality). In as much as physical contact hours continues to remain necessary in many service sectors whereas these contact hours remain a mark of quality for QE. Design considerations here include the environment and the systems used. Service procedures, facilities and systems should be designed with the customers in mind, as well as the 'product' and the human resources. The sad state of affairs is that most of Kenyan Universities lack very severely in the technical aspects that make it possible for the lecturer to provide these services. In order to demonstrate global competitiveness most universities arrange for acquisition of ISO certification which is a yardstick for quality. After achieving the coveted ISO certification, do these universities provide the technical aspects to support lecturers in providing $\mathrm{QE}$

According to UNESCO QEmust always seek to realize the six goals which are: 1) foster national unity; 2) prepare and equip the youth with knowledge, skills and expertise to enable them to play an effective role in the life of the nation; 3 ) serve the needs of national development; 4) provide for the full development of talents and personality; 5) promote social justice and morality, social obligations and responsibilities; and 6) foster positive altitudes and consciousness towards other nations. Education has, therefore, been seen as a fundamental strategy for human capital development and a crucial vehicle for enhancing the quality of life(UNESCO, 2005).

On one hand, QE is a multi-dimensional concept with various interpretations. These include: 1) quality as Excellence: Seen in terms of high standards attainable by only afew (traditional university view); 2) quality as Perfection: "Zero Errors or Defects". The view for mass production in industry; 3) quality as value for money: Returns to investment, Accountability to the Public on expenditure; 4) quality as transformation: Seen as change with added value; 5) quality as meeting Customers' needs: Making the customer satisfied. Used mainly in industry. Students are customers as well as products, hence in this case, needs and wants may be different (students); 6) quality as conformance to standards: Meeting pre-determined standards, Quality as fitness-forpurpose: Quality is measured against stated mission and objectives; 7) quality as fitness for purpose and fitness of purpose.

On the other hand, Quality Assurance is a systematic and continuous attention to quality and quality improvement or enhancement. It has two (2) Components: 1) Internal QA: Refers to the Institution's mechanisms for ensuring and improving its own quality and 2) External QA: Refers to periodic monitoring of quality of University Education at institutions by an External Quality Assurance agency or body(CUE, 2014).

\subsection{Lecturer Qualification and credentials According to CUE}

Research experience, credentials, self-efficacy, professional activities, and selected classroom practices are viable components of an aggregate lecturer quality measure,(Elaine Carlson, Hyunshik Lee, \& Karen Schroll Westat, 2004; CUE, 2014). Lecturers' promotion is pegged on quality research for instance for one to be promoted to professor, they would now have at least a minimum equivalent publication points from scholarly journals(CUE, 2014).The publication points are based on the number of books published and level targeted such as high school or university. For example, one university book is equivalent to four points while one tertiary level book has two points. The guidelines also require a professor to supervise postgraduate students besides teaching.

Improving quality of instruction is a central component to virtually all research done and documented on QE. It has been observed that unfortunately, policy recommendations often ignore existing evidence about lecturer labor markets and the determinants of lecturer effectiveness in the classroom. The importance of lecturer quality in the determination of student achievement, and the extent to which specific observable characteristics often related to hiring decisions and salary explain the variation in the quality of instruction. The evidence is applied to the comparison between policies that seek to raise quality by tightening the qualifications needed to enter university teaching terrain and policies that seek to raise quality by simultaneously loosening entry restrictions and introducing performance incentives for lecturers and administrators(Eric A. Hanushek Steven G Rivkin, 2006).

Certification or and admission into any university's academic staff is a measure of lecturer credentials that combines aspects of knowledge about subject matter and about teaching and learning. Standard certificate generally means that a lecturer is prepared and approved according to CUE guidelines on criteria and guidelines for appointment and promotion of academic staff. Lecturers then must have one or more areas of specialization and basic skills, subject matter knowledge, and/or teaching knowledge or skills as the basis for the initial or continuing license or for admission to University Academic Staff(CUE, 2014), (Darling-Hammond, 2000). A 
vital skill for lecturers is to be able to translate academic knowledge into practice. Chireshe (2011) study on Effective and Ineffective Lecturers: University Students' Perspective in Zimbabwe investigated university students' perspective on effective and ineffective lecturers revealed that effective lecturers were well organized, competent, always involved students, friendly and readily available; that ineffective lecturers did not plan for their lectures, came late for lectures, were not knowledgeable, were not contributing to students' seminar presentations, were intimidating students, were not involving students, were boasting about their qualifications and family and were biased in their marking. An effective lecturer is one who is perceived as one who: is knowledgeable in the subject area, has personality attributes that promote rapport with students, is organized, punctual, delivers well prepared lectures, gives clear explanations, gives out handouts and extra reading materials, is fair and actively engages students in the learning process.

\subsection{Lecturers' Quality Research and Challenges}

From existing literature, much attention has been paid to the Student. Much of the evaluation is on the basis of interactions during the academic program. The lecturer has been neglected. Transforming lecturers into active participants in sustainable development and individuals who fulfill all of the other educational goals when they graduate, would translate into quality.

It is well documented that the double in - take and parallel programs have caused a shortage of physical facilities in public universities in Kenya;lecturers' teaching load is prohibitively heavy with semesters that run back to back and no break for lecturers and dearth of financial sources(Calleb O Gudo, Maureen A. Olel and Ibrahim O., November 2011). Other Challenges include very little or no resources, undependable communication means, deficiencyof equipment and Internet access, absenceof training, lack of research and secretarial assistance, and help from colleagues and supervisors; non-availability of research grants and when they are available lecturers are ignorant of such grants; the Governments and universities' initiatives on research funding and support are relatively insignificant within the wider context of potential means of allocating funds. Individual universities' decision remains a prevailing force, amplified by peer review and institution-level performance-based allocation. These challenges are made worse the fact that most of the Kenyanuniversitiesare young and struggling financially.

A challenge that many lecturers are having to deal with is meeting CUE's new guidelines on the minimum requirements to be a university don: be a PhD. The deadline to achieve this coveted $\mathrm{PhDs}$ is set for the year 2018. This brings to an end the current criteria where each university had a different formula of promoting and appointing lecturers(Nganga, 2017)(CUE, 2014).

Orientations of new lecturers are conspicuously absent. The new staff must find their way: the school in which they belong; the course descriptions for the various units to be taught, generate a course outline and find teaching resources. Next season if that course is taught by a different lecturer the course outline will be different. Since lecturers do not have the same resources the content will be different. It becomes challenging then to discuss quality in such situations. Worse still, if they are not equipped with pedagogical skills, the content they have may not be effectively communicated to the customer.

Universities, especially those in the developing economies, are challenged when it comes to resources. There has been exponential enrolment in primary and consequently, secondary schools. As a result, many governments have been compelled to open new universities in order to absorb the increased numbers of those who qualify to join and also to increase accessibility in line with the education-for-life agenda. It is no wonder that most of these universities have 'innovativeness' as part of their mission because it is nearly the only way to manage the situation. Although UNESCO requires governments to commit $20 \%$ of its budget to education and a further $20 \%$ of aid to the same, higher education has suffered neglect in the past and catching up is an exhausting exercise(UNESCO, 2005).

\section{Research Strategy}

This paper is a qualitative desk - top research. Various demands on the lecturer are discussed: The CUE regulations on lecturer upward mobility, universities trends in Kenya, UNESCO educational requirements and current National goals and elsewhere were discussed. The dilemma that lecturers find themselves in as they navigate their careers between publishing or perishing; providing QE as set out by CUE provisions and other stakeholders; without any break as semesters run back to back due to the double intake, privately sponsored students programs phenomena (CUE, 2014), little or no funding for lecturer development are addressed; finally the paper suggested some recommendations.

\section{Conclusion And Recommendations}

As demonstrated in this paper the major discussions on QE suggest that although it is difficult to pin down the definition of $\mathrm{QE}$, it is in order to agree that $\mathrm{QE}$ depends on the quality of lecturers (The Aga Khan University, 2006). The major stakeholders who define the education agenda like the ministry of education, 
relevant government agencies and UNESCO provide a framework for operation. However, they should make sure to leave room for adaptation to the local environmental dynamics. It then behooves each university to identify its unique circumstances, whether challenging or opportunity oriented, to create a niche for themselves and develop it into a formidable competitive edge. Maasai Mara University (MMU), for instance, is sandwiched between two world renowned phenomena: The Mau Forest which suffers near-depletion and the Maasai Mara Game Reserve. Clear policy regarding participation in the restoration of the Mau will attract resources that will not only support the process but whose spill-overs in form of manpower development and civic education, will go a long way in contributing to sustainable development, which is a part of the University mission. Development of a world class tourist destination would, over and above other benefits, transform the institution into a pacesetter in the industry as it combines knowledge, research and the natural endowment.

The Kenyan government and universities need to take serious steps to ensure that research is placed as a top urgency in their strategic plans and personnel professional development programs funding. Universities reacted to the crisis of the increased Kenyan Certificate of Secondary Education (KCSE) grandaunts who needed to enroll for university education by coming up with the double in - take and parallel programs which caused a shortage of physical facilities in public universities in Kenya; lecturers' teaching load became prohibitively heavy with semesters that run back to back and no break for lecturers and dearth of financial source. Long term plans should be put in place on the development of the infrastructure of individual universities to cater for double in - take and parallel programs;investment in modern information technology to enhance university teaching and collaborationbetween the government and private sector, including private universities as equal partnersin the provision of QE; and semester dates should be restructured to accord lecturers a recess to better work on meeting the criteria for promotion for lecturers.

Quality and its continuous improvement is an organization-wide responsibility. In most universities it comes across as the responsibility of management alone who in turn lean very heavily on lecturers to provide this QE. Universities should borrow a leaf from the corporate world. Lecturers, who are the medium through which the quality is delivered often, should not be left to dwells in limbo; there development should not be ignored and delivery in terms of skills and contents assumed to be what is expected. In the corporate world, once recruitment is done the new employee is taken through an orientation process so that they can understand the organization, its vision and mission and to 'join the family'. Expiations are clearly spelt out and, resources for performing the job are provided. In the course of time, after identifying the strengths of the individual she/he is taken through specific development programs.

To alleviate the problem of funding, upcoming universities could also identify businesses that would profit them and seek partnerships to develop them for future sustainability. Some universities around the world have established business enterprises that generate income to support their operations. The new initiative by UNESCO to get businesses to back education is timely and universities can proactively log into it with the view of investing in projects that will ensure financial sustainability of the institutions in the long run(UNESCO, 2005). MMUfor instance, could consider a tourism facility tending towards hotel and hospitality. In the long run the university should run its research programs, develop staff and infrastructure, etc. without much strain. Such a development would also provide training and job opportunities, to preserve the education component from commoditization, provide work-study opportunities for needy students, student independence, etc.

Both qualifications and credentials and immense support for lecturers by the Government and CUE are essential. In addition, behavioral factors like organization, vulnerability, approachability also count for quality. There are also suggestions that incentives can also determine the lecturer's quality of delivery. With globalization, regional integration, development of virtual universities and distant learning and for Kenya, devolution, matters of QE will become even more complex. It is urgent that each university finds a mechanism of engaging all its stakeholders and not only define quality but establish structures for implementing the same. Seeking ISO certification is a good housekeeping move and for most local universities and a foundational step towards provision of total quality. Incentives and rewards for university lecturers should be provided systematically and substantially with the linking of performance appraisal with research.

\section{References}

[1]. Agoki, D. K. (2015). A Comparative Study of Relationship Marketing and Transactional Marketing in the Services Sector - A Case of Cyber Cafes in Kisii Town Kenya. Journal of Technology and Social Economic Development, 5th Edition.

[2]. Billing, D. (2004). International Comparisons and Trends in External Quality Assurance: Commonality or Diversity. Journal of Higher Education, Vol. 47, Issue 1, 113 - 137.

[3]. Calleb O Gudo, Maureen A. Olel and Ibrahim O. (November 2011). University Expansion in Kenya and Issues of Quality Education: Challenges and Opportunities.nternational Journal of Business and Social Science, Vol 2 No. 20,103 - 104.

[4]. Chireshe, R. (2011).Effective and Inneffective Lecturers.Anthropologist, Vol. 13 (4), 265 - 269.

[5]. College Excellence Program. (2015). From College to Jobs: Making Sense of the Labour Market Returns to High Education. Washington, DC 20036-1133, Washington DC : The Aspen Institute.

[6]. CUE, C. f. (2014, October 27th).Commision for University Education.Harmonization Criteria and Guidelines foenya. Nairobi, Kenya: CUE. 
[7]. Darling-Hammond, L. (2000). Teacher Quality and Student Achievement - A review of State Policy Evidence. Education Policy Analysis Archives.

[8]. Demming, W. E. (1993). The New Economics for Industry, Government, Education, 2nd Edition. Massachusetts: Massachusetts Institute of Technology.

[9]. Elaine Carlson,Hyunshik Lee, \& Karen Schroll Westat. (2004). Identifying Attributes of High Quality.Teacher Education and Special Education, Volume 27, No. 4, 000-000.

[10]. Eric A. Hanushek Steven G Rivkin. (2006).Handbook of the Economics of Education, Vol. 2.

[11]. Morey, A. (2006).Handbook of the Economices of Education, Vol. 2. California: San Diego State University.

[12]. Newton, J. (2000). Feeding the Beast or Improving Qualtiy: Academic Perceptions of Quality Assurance and Qualty Monitoring . Quality in Higher Education: Vol. 6, Issue 2, 153 - 163.

[13]. The Aga Khan University.(2006). Quality in Education: Teaching and Leadership in Challenging Times. Vol.1. The International Conference at Aga Khan University Institute for Education Development (p. xii). Karachi: Aga Khan University Institute.

[14]. UNESCO.(2005, January 17th - 18th).UNESCO/OECD Guidelines on "Quality Provision In Cross-Border Higher Education" Drafting Meeting 3. UNESCO's Capacity Building Activities In Qualifications, Recognition Quality Assurance And Accreditation:Towards A Coherent Framework. Paris, France: UNESCO. 